\title{
Do Fair Trade Labels Bias Consumers' Perceptions of Food Products? A Comparison between a Central Location Test and Home-Use Test
}

\author{
Joachim J. Schouteten ${ }^{1, *(\mathbb{D}}$, Xavier Gellynck ${ }^{1}$ and Hendrik Slabbinck ${ }^{2} \mathbb{C}$ \\ 1 Department of Agricultural Economics, Ghent University, Coupure Links 653, 9000 Gent, Belgium; \\ xavier.gellynck@ugent.be \\ 2 Be4Life, Department of Marketing, Innovation and Organisation, Ghent University, 9000 Gent, Belgium; \\ hendrik.slabbinck@ugent.be \\ * Correspondence: joachim.schouteten@ugent.be
}

Citation: Schouteten, J.J.; Gellynck, X.; Slabbinck, H. Do Fair Trade Labels Bias Consumers' Perceptions of Food Products? A Comparison between a Central Location Test and Home-Use Test. Sustainability 2021, 13, 1384. https://doi.org/10.3390/su13031384

Academic Editor: Claudia Bazzani Received: 31 December 2020

Accepted: 25 January 2021

Published: 28 January 202

Publisher's Note: MDPI stays neutra with regard to jurisdictional claims in published maps and institutional affiliations.

Copyright: (c) 2021 by the authors. Licensee MDPI, Basel, Switzerland. This article is an open access article distributed under the terms and conditions of the Creative Commons Attribution (CC BY) license (https:// creativecommons.org/licenses/by/ $4.0 /)$.

\begin{abstract}
Consumers are paying more and more attention to ethical and social criteria during grocery shopping. As a result, Fair Trade products which are certified to address global supply chain issues (e.g., forced labor, working conditions, fair pay), are gaining popularity. However, it is unclear to which extent Fair Trade labels might influence how consumers perceive such labelled food products. The aim of this research was to examine the potential effect of Fair Trade labels on several measurements (overall liking, sensory profiling, emotions, willingness-to-pay and kCal estimations). Furthermore, tests were carried out at a sensory lab and at home to examine if the evaluation context might impact the label effect. In total, 179 consumers participated in this study of which 90 carried out the test in the sensory test facilities (central location test-CLT) and 89 at home (home-use-test-HUT). Participants evaluated three pairs of food products (nuts, juice and chocolate) of which one was labelled as conventional and the other one as Fair Trade. However, participants were each time evaluating the same Fair Trade product. Results showed that the Fair Trade label increased the overall liking. For the juice and chocolate, a higher willingness-to-pay was found when the product was labelled as 'Fair Trade' while no effect of the label was established for the nuts. The Fair Trade label did not affect the kcal estimation of the samples. The Fair Trade label had a rather limited influence on the sensory and emotional profiling of the food products. Furthermore, the results of the CLT and HUT were highly similar indicating that the evaluation context has little impact on the labelling effect.
\end{abstract}

Keywords: consumer; sensory; emotion; acceptance; willingness-to-pay; sustainable; label; halo; Fair Trade certification

\section{Introduction}

Ethical and social criteria are gaining importance as criteria for grocery shopping. Examples of such ethical values are working conditions during production, human rights and animal welfare [1]. Ethical consumerism does even not only refer to these classical 'Fair Trade aspects' but goes broader as it also encompasses matters as prevention of child labor, the employment of handicapped people, protection of the tropical rainforest and reduction of greenhouse gasses [2]. Ethical consumerism can be seen as a response of the growing consumers' criticism regarding the globalization of agricultural production resulting in questions regarding economic, environmental and social consequences of global trade [2].

In this context, Fair Trade food production is of interest. Fair Trade is an innovative value chain with the objective to improve the trade position of small-scale farmers [3]. Fair Trade producers receive in general a higher price than non-Fair Trade producers but must meet labor, sustainable farming, governance and democratic participation criteria [4]. As such, Fair Trade can be seen as sustainability certification scheme [5]. In addition to the 
price, a social premium is paid which is mandated for community use [6]. A review by Le Mare [7] concluded that most studies found a significant impact of Fair Trade production on social and economic aspects of development, contributing to the capacity to improve and diversify livelihoods in the global South. From a point of view of sustainability, Fair Trade production is relevant for several SDG's of the United Nations such as goal 1 (end poverty in all its form everywhere), goal 2 (end hunger, achieve food security and improved nutrition and promote sustainable agriculture), goal 8 (promote sustained, inclusive and sustainable economic growth, full and productive employment and decent work for all, goal 12 (ensure sustainable consumption and production patterns) and goal 17 (strengthen the means of implementation and revitalize the global partnership for sustainable development) [8].

Fair Trade label initiatives created an international certifying body, the Fairtrade Labelling Organization International [4]. This organization ensures that Fair Trade producers comply with international production standards. Products which meet their standards are permitted to place the international Fair Trade label on the products and products' packages. Fair Trade labels are therefore a way to communicate to consumers that products have been produced in line with the Fair Trade Standards. Key to the success of Fair Trade products is that consumers recognize, understand and accept Fair Trade labels [9]. This is even more important as consumers cannot accurately evaluate if a product has been Fair Trade produced. Therefore, Fair Trade labels can be seen as a credence attribute just like organic food products [10]. As such, these Fair Trade labels can play a role in consumers' food choices [11]. Research undertaken on how consumers perceive Fair Trade labelled food products is therefore essential to further increase Fair Trade consumption and therefore socially sustainable food production.

Research has largely focused on consumers' attitudes and motivations towards Fair Trade food consumption while less research has been conducted on consumer preferences for Fair Trade products [12]. To date, focus lied primarily on the willingness-to-pay (WTP) of Fair Trade products. Zerbini, et al. [13], applying the theory of planned behavior [14], showed a positive effect of attitude towards the product, personal norms and empathy on purchase intention. Research of Konuk [1] has found that consciousness for fair consumption, environmental concern, trust in Fair Trade label and consumer innovativeness impacted consumers' willingness to buy and willingness to pay for Fair Trade food products. WTP of Fair Trade products has been specifically studied for some food products, namely coffee $[5,15,16]$, yellow chili peppers [17] and chocolate [18-20]. Out of these different studies, it can be concluded that a premium WTP may occur for food products but the effect of a Fair Trade label might differ between consumer segments. Next to the WTP, some research has examined the influence of Fair Trade labels on consumers food preferences and product evaluations. Sensory attributes of pineapple labelled as Fair Trade were perceived as stronger for consumers with a positive attitude towards Fair Trade compared to conventional pineapple [21]. However, it should be noted that the opposite was found for consumers with a negative attitude towards Fair Trade products leading to little effect of a Fair Trade label on consumer's liking of pineapple when considering the data of all the subjects. Poelman, Mojet, Lyon and Sefa-Dedeh [21] hypothesize that when consumers are split in subgroups based on explicitly measured attitudes, the judgements are shifted in a direction which is consistent with the individual's beliefs. So Fair Trade information will have a positive effect on the liking and perception of foods for consumers with a positive attitude while a negative effect will be established for consumers with a negative attitude. When considering the overall sample, consisting of some people with positive and some with negative attitudes, there was little overall effect of the Fair Trade label. A study with 64 Swedish students found that a Fair Trade label (incl. background information about the Fair Trade label) increased the overall liking score of orange juice if participants attached more importance to 'warm relationships with others' [22]. Another study found that adding Fair Trade label on the package increased the overall taste perception of coffee and chocolate when evaluated by German undergraduate students [23]. But also in non-Western countries, such as in China, Fair Trade information leads to a 
better evaluation of a food product as the Fair Trade logo enhanced the taste evaluation of Chinese tea by local Chinese undergraduate students [24]. Furthermore, research by Schuldt, et al. [25] indicated that Fair Trade products could also induce a health halo as students perceived chocolate foreseen with a Fair Trade label as having less calories than conventionally produced chocolate. The focus of the aforementioned studies lies on examining a potential Fair Trade label effect on the overall acceptance of the food products, with only one study [21] examining the effect of Fair Trade labels on (a limited) number of sensory characteristics. Given that that study by Poelman, Mojet, Lyon and Sefa-Dedeh [21] dates already from 2008, there is a lack of recent work which examined the potential effect on Fair Trade labels on consumers sensory profiling of food products. Moreover, there is growing interest the last decade to also examine the emotional associations consumers attach to food products [26] which has not yet been studied for Fair Trade labelled products. Exploring the emotions evoked by Fair Trade labelled products might provide additional insights. If these products lead to more positive emotions (for instance because consumers feel good to support the cause and it resemble their values [9]) then these positive emotions might warrant a price premium for Fair Trade products.

Sensory tests are typically conducted in a central location (CLT) in order to limit the influence of panelist bias and confounding non-product factors on the evaluations of food products $[27,28]$. However, real eating behavior takes rather place in a specific physical (e.g., at home, in a restaurant, ... ) and social (e.g., with friends, family, ... ) context [29]. In order to higher the ecological validity of sensory tests, there has been a momentum for conducting sensory tests beyond the classical CLT context [30]. To date, home-usetests (HUT) were the most applied alternative contexts to perform sensory and consumer research [31]. Jaeger and Porcherot [31] concluded in their review paper that there is no proof that HUT has higher product discrimination compared to CLT. They further highlight that the conclusions, drawn upon hedonic product tests with CLT and HUT, cannot be generalized to other perceptual products responses such as emotions. Previous research found that the context had only a limited impact on the sensory profiling [32], while several studies observed that emotional associations of food products were influenced by the context [32-34]. The aforementioned studies [21-25] which examined the impact of a Fair Trade labels on product evaluations (e.g., sensory acceptance) were all performed in a CLT settings. Four studies [21,23-25] took place on the university campus while detailed information of the CLT from one study [22] was not available. As a consequence, it is unclear if a fair trade labelling effect might occur when testing is taking place at home. A CLT test induce more a feeling for consumers that they are participating in an experiment [35] which might lead to participants more providing socially desirable answers. So prior research might have overestimated the impact of Fair Trade labels. Given the limited knowledge of Fair Trade labels on consumer perceptions [10], the objective of this study is to examine the impact of written information about the production method (Fair Trade vs. conventional) on consumer food product evaluations going beyond the classical overall acceptance measures by also including sensory and emotional profiling of the product samples. To date, it is unclear if the fair trade label might also affect consumers' evaluations of food products when they are consumed in a more natural consumption context like at home. Moreover, there is a growing interest to perform sensory tests in a natural consumption context to increase the ecological validity of the experiment $[31,36]$. Therefore this study opted to collect data not only in a traditional sensory lab context (CLT) but also at home (HUT) to examine if the evaluation context might impact potential labelling effects.

\section{Materials and Methods}

\subsection{Participants}

Participants were recruited out of a database with interested volunteers and at a local university campus. They were randomly assigned to perform the test either at the sensory facilities of Ghent University or at home. They were informed that the study was about 
the evaluation of Fair Trade products during the informed consent. The study has been approved by the ethical board of the Faculty of Economics and Business administration (Ghent University) and participants did not receive any reimbursement for their participation. Participants needed to be product-users and not allergic to ingredients in the product samples (soy, milk and nuts). Participants were recommended not to smoke/consume any food or beverage at least an hour before starting the test. In total, 179 participants took part of which the majority were female. Age range was between 18 and 67 years old, although the mean age was only 23.9 at the CLT and 25.0 at the HUT. A significant difference $(\mathrm{t}(177)=-3.443, p=0.001)$ regarding the hungry feeling between the CLT and HUT groups was found. The participant at home indicated to a higher extent that they were hungry. Furthermore, a significant difference $(\mathrm{t}(177)=-2.268, p=0.025)$ was found regarding the restraint status with people at the HUT were more restraint compared to those at the HUT as a higher score reflects a higher restraint status. This is also in line with the fact that $18 \%$ of the HUT declared to be actively following a diet which was significantly higher $(\chi 2(1, N=179)=5.311, p=0.021)$ compared to the diet status of persons executing the task at the CLT.

More detailed information about the characteristics of the participants can be found in Table 1.

Table 1. Socio-demographic information (gender, age, hunger, thirst, diet, BMI and restraint status) of the consumer panels of the study. Values are expressed as \% of participants or means (S.D.).

\begin{tabular}{ccc}
\hline & CLT $(\boldsymbol{n}=\mathbf{9 0 )}$ & HUT $(\boldsymbol{n}=\mathbf{8 9})$ \\
\hline Gender (\% female) & 54.4 & 64.0 \\
Age (S.D.) & $23.9(5.8)$ & $25.0(7.2)$ \\
Hunger & $30.1^{\mathrm{b}}(30.0)$ & $44.6^{\mathrm{a}}(26.2)$ \\
Thirst & $46.6(29.7)$ & $49.0(25.1)$ \\
Diet (\%) & $6.7 \%$ & $18 \%$ \\
BMI & $22.2(4.0)$ & $22.1(2.5)$ \\
Restraint status & $2.3^{\mathrm{b}}(0.8)$ & $2.5^{\mathrm{a}}(0.8)$ \\
\hline
\end{tabular}

$\overline{\mathrm{a}, \mathrm{b}}$ means that that the characteristic was significantly different between the participants of the CLT and HUT.

\subsection{Products and Presentation Mode}

Participants evaluated pairs of products in this study, of which one was labelled as 'conventional' while the other was labelled as 'Fair Trade'. However, participants received two times the same (Fair Trade produced) samples in each pair as the goal of this study was to assess the impact of Fair Trade labels. Only verbal terms were used to prevent the impact of other package information. The samples were foreseen with 3-digit codes and presented in odorless cups, the additional product information was only presented within the electronic questionnaire. Hence, the three digit code was the only feature that distinguishes the two samples when they were presented in each product pair. When the participants were evaluated the product pairs in the software, one 3-digit code of each pair was accompanied with the term 'conventional' while the other was labelled as 'fair trade'. This research opted only to use verbal words to limit potential influence of other package cues.

In total, participants needed to evaluate three pairs of product samples. Based upon the availability of Fair Trade products on the market, the researchers opted to work with nuts, chocolate and orange juice. Consequently participants were provided with 6 product samples in total, so 2 nuts portions, 2 chocolate portions and 2 orange juice portions. All samples were bought in the local supermarket and were from the same batch. The evaluation of the pairs (nuts, chocolate and fruit juice) and labeling (conventional and Fair Trade) within a pair were balanced using William's Latin Square Design to prevent order and carry-over effects [37]. The sample sizes were sufficient to allow 3 bits or sips and participants were instructed to clean their palate with water during product evaluations. 


\subsection{Questionnaire}

The questionnaire was administered with the EyeQuestion v. 4.9.4 (Logic8Bv, Elst, The Netherlands) software.

Participants specified if they were hungry/thirsty using a score from 0 (not at all) to 100 (extremely). Next, they indicated if they 'currently were on a diet to lose weight' (yes/no) [38].

The evaluation of a sample was a three-step procedure with the assessment of (i) the overall liking, (ii) sensory attributes (iii) emotional conceptualizations. A 9-point hedonic scale ( 1 = dislike extremely, 9 = like extremely) was used for the assessment of the overall acceptance during the first step. Next, the sensory and emotional profiling took place using the check-all-that-apply (CATA) method. Terms were determined by the researchers using input from 20 non-trained consumers who evaluated a list of potential sensory and emotional terms based upon pilot work and prior literature [39]. The list with sensory and emotional terms can be found in Table 2. Sensory and emotional terms were presented following a balanced presentation order design (William's Latin Square) [40]. Participants were requested to estimate the number of kilocalories of a snack portion [41] and their willingness to pay (in $€$ ) for a snack portion [42]. Once they finished the evaluation of all the samples, they were asked to provide any remarks regarding the tasted samples (open-ended question) [43].

Table 2. Overview of the sensory and emotional terms used for the different food products.

\begin{tabular}{|c|c|c|c|}
\hline & Nuts & Chocolate & Juice \\
\hline \multirow[t]{14}{*}{ Sensory terms } & Chicken stock & Brown & Aftertaste \\
\hline & Salty & Melting & Bitter \\
\hline & Sweet & Sweet & Intense flavor \\
\hline & Crunchy & Bitter & Light color \\
\hline & Bland & Creamy & Natural taste \\
\hline & Roasted & Cocoa flavor & Off-flavor \\
\hline & Bitter & Granular & Orange aroma \\
\hline & Visible salt & Milky & Orange color \\
\hline & Oily & Cocoa aroma & Orange flavor \\
\hline & Brown color & Mouthfeel & Pulp \\
\hline & Earthy & Sticky & Sour \\
\hline & Natural & Aftertaste & Sweet \\
\hline & & Smooth & Thick \\
\hline & & Firm & Watery \\
\hline \multirow[t]{18}{*}{ Emotional terms } & Bored & Calm & Calm \\
\hline & Calm & Desire & Desire \\
\hline & Contented & Disappointed & Disappointed \\
\hline & Disappointed & Discontented & Discontented \\
\hline & Discontented & Dissatisfied & Disgust \\
\hline & Disgust & Disgust & Dissatisfied \\
\hline & Dissatisfied & Energetic & Energetic \\
\hline & Friendly & Enthusiastic & Enthusiastic \\
\hline & Frustrated & Glad & Glad \\
\hline & Good & Good & Good \\
\hline & Interested & Guilty & Guilty \\
\hline & Happy & Happy & Happy \\
\hline & Joyful & Irritated & Irritated \\
\hline & Pleasantly surprised & Nostalgic & Warm \\
\hline & Satisfied & Pleasant & Pleasant \\
\hline & Irritated & Sad & Sad \\
\hline & Unpleasantly surprised & Satisfied & Satisfied \\
\hline & Steady & $\begin{array}{c}\text { Unpleasantly surprised } \\
\text { Worried }\end{array}$ & $\begin{array}{c}\text { Unpleasantly surprised } \\
\text { Worried }\end{array}$ \\
\hline
\end{tabular}

Following the sensory evaluation of the samples, some attitudinal measurements were asked. In order to assess participants restrained eating, they needed to answer 10 questions derived from the Dutch Eating Behavior Questionnaire (DEBQ) on a 5-point scale ranging from 1 (never) to 5 (very often) [44]. A "restrained eating" score was created by averaging the scores of these 10 items (Cronbach's $\alpha=0.897$ ). Next, consumers were asked how many 
out of 10 products are Fair Trade when they go grocery shopping [43]. Also, participants were asked to which degree they agreed with the statement ' I usually read nutrition labels on food product' measured on a 7-point scale ( $1=$ totally disagree $-7=$ totally agree) [42] Further, four items regarding involvement towards Fair Trade products were included using a 7 -point scale $(1=$ totally disagree $-7=$ totally agree). These four items were "Fair Trade means a lot to me", "I care a lot about Fair Trade food", "Fair Trade is very important to me" and 'I appreciate Fair Trade food very much" [45]. A single index for "Fair Trade involvement" was obtained by averaging the scores from those four items (Cronbach's $\alpha=0.935$ ). Furthermore, three items related to personal values have been included given their effect on Fair Trade consumption. These three items were "Equality (equal opportunity for all, brotherhood) is very important to me", "Social fairness (correct unfairness, rescue poor) is very important to me" and "Respect for the environment is very important to me" and participants were asked to which extent they (dis)agree with each statement on a 7 -point scale $(1=$ totally disagree $-7=$ totally agree) [46]. By averaging these three items, a single index for "personal values" was obtained (Cronbach's $\alpha=0.898$ ).

\subsection{Data Collection Procedures}

\subsubsection{Central Location Test}

Testing took place between 10 a.m. and 6 p.m. at the sensory facilities of a local university. Participants were seated in individual booths to evaluate the samples in a controlled environment. Products were served in transparent odorless cups foreseen with a three-digit code. Nuts and chocolate were served at room temperature $\left(21^{\circ} \mathrm{C} \pm 0.5^{\circ} \mathrm{C}\right)$ while juice was presented after storage in a fridge with a temperature of $6^{\circ} \mathrm{C}$. Participants were provided with one pair at the time.

\subsubsection{Home Use Test}

Participants of the HUT received the products and test instructions during a visit of the researcher. In order to maximize the similarity with the CLT Test, consumers were instructed to complete the consumer test without time intervals [47]. Further, they were free to complete the consumer test when and with whom they wanted to heighten the ecological validity. Participants filled in the Internet-based consumer test, using the EyeQuestion Software v4.9.5 (Logic8 BV, Elst, The Netherlands), through a link provided by the researchers. They were clearly instructed to personally consume a minimum amount of each sample ( 1 bite/sip for overall liking, 1 bite/sip for sensory profiling and 1 bite/sip for emotional profiling) which was also stated in the questionnaire [35]. The procedure for the sample evaluation was the same as for participants of the CLT test (e.g., balanced sample presentation order and palate cleansing).

\subsection{Data Analysis}

Mixed model ANOVAs (within subjects factors: product (chocolate/juice/nuts) and label (Fair Trade/conventional); between subjects factor: context (CLT/HUT)) were performed separately on the overall liking scores, WTP and Kcal estimations to examine if the effect of the labels differed between the CLT and HUT context for each of the three food samples [35].

Questions related to four moderators (purchase behavior, reading of nutrition labels, involvement with Fair Trade products and personal values) were included in this questionnaire. Participants were first divided into two groups for each of these moderators corresponding to a high or low frequency/score [43]. Following upon this, a series mixed ANOVAs were conducted analyzing the effect of the label on the overall liking, WTP, and Kcal estimations (within-participant factor) and each moderator and the context as between-participant factor for each product (chocolate/juice/nuts) separately. T-tests were carried out to examine the potential label effect for that specific moderator for the CLT and HUT separately when a significant interaction of the within-participant factor $x$ moderator $x$ context was found. If only a significant interaction effect was observed for the within- 
participant factor $\mathrm{x}$ moderator, two paired-samples t-tests were conducted to determine were the effect of the Fair Trade label was less pronounced among the participants for that specific moderator [42,43].

The Mc Nemar test was applied to detect significant differences in the frequency of selection of sensory/emotional terms between the labelled samples for each context (CLT/HUT) [48,49].

All statistical analyses were carried out using SPSS Statistics 26 (IBM, Armonk, NY, USA) considering a significance level of 0.05 .

\section{Results}

\subsection{Consumption Behavior}

Participants claimed that around 3.5 out of 10 products they bought were Fair Trade. Out of 10 products, the participants at CLT bought on average 3.1 Fair Trade products (S.D. $=2.5)$. However, this was significantly less compared to the participants at home who claimed that on average 3.8 out of 10 (S.D. $=2.3$ ) products they bought were Fair Trade $(\mathrm{t}(177)=2.038, p=0.043)$. When grouping the participants into lower/higher Fair Trade buying frequency, 34 participants at the CLT test and 46 of the HUT were considered as persons with a higher Fair Trade buying frequency.

On average, participants answered neutral on the question if they usually read the nutrition labels on food products which was measured on a 7-point scale $(1=$ totally disagree $-7=$ totally agree). The mean score for participants of the CLT was 4.7 (S.D. $=1.9$ ) and for the HUT 4.5 (S.D. $=1.8)$ which was significantly not different $(p=0.329)$. At the CLT, 55 participants were classified as having a higher frequency of reading nutrition labels while 46 participants at the HUT were classified as persons with a higher frequency of reading nutrition labels.

The involvement into Fair Trade products was on average neutral, reflected in a mean score of 4.3 (S.D. = 1.4) for the participants of the CLT and a mean score of 4.0 (S.D. = 1.4) for the participants performing the test at home. No statistical differences were found between the involvement scores of the CLT and HUT group ( $\mathrm{t}(177)=1.668, p=0.093)$. In total 47 out of 90 persons were labelled as having a higher involvement for Fair Trade products at the CLT test while also 47 persons (out of 89) of the HUT were classified as having a high involvement for Fair Trade products.

On average, the participants scored high on personal values (equality, social fairness and respect to the environment) given that the mean score for the participants at the CLT was 5.9 (S.D. $=0.9$ ) and HUT was $5.6($ S.D. $=1.3$ ) on a scale ranging from 1 (low importance) to 7 (high importance). Statistical analysis ( $\mathrm{t}(157.135)=1.572, p=0.118$ ) found no significant difference between participants of the both locations for their importance on personal values. When grouping the participants, 50 participants of the CLT and 47 of the HUT were classified as giving a higher importance to personal values.

\subsection{Overall Liking}

The 3-way ANOVA indicated a significant interaction effect of Product $X$ Context (F $(1.932,354)=3.513, p=0.032)$, with higher overall liking scores found for the chocolate and nuts when the tests took place at the lab while the juice samples received higher scores during the HUT. Further, an effect of the label was found $(\mathrm{F}(1,177)=18.326, p<0.001)$ with a slightly higher mean overall liking score when a sample was foreseen of a Fair Trade label (0.242). Mean overall liking scores for the products in the two different contexts are listed in Table 3. 
Table 3. Mean overall liking and S.D. scores (measured on 9-point scale ranging from $1=$ dislike extremely to $9=$ like extremely) for the labelled products separately for the CLT $(n=90)$ and HUT $(n=89)$ context.

\begin{tabular}{cccccc}
\hline & \multicolumn{2}{c}{ Fair Trade } & \multicolumn{2}{c}{ Conventional } \\
\cline { 2 - 6 } & Mean & S.D. & Mean & S.D. & $p$ \\
\hline CLT & & & & & \\
Chocolate & 7.0 & 1.3 & 6.8 & 1.4 & 0.138 \\
Juice & $6.2^{\mathrm{a}}$ & 1.6 & $5.8 \mathrm{~b}$ & 1.7 & 0.001 \\
Nuts & 6.5 & 1.1 & 6.3 & 1.4 & 0.138 \\
\hline HUT & & & & & \\
Chocolate & 6.8 & 1.3 & 6.6 & 1.5 & 0.088 \\
Juice & 6.5 & 1.4 & 6.3 & 1.4 & 0.084 \\
Nuts & 6.3 & 1.6 & 6.1 & 1.5 & 0.114 \\
\hline
\end{tabular}

$\overline{\mathrm{a}, \mathrm{b}}$ different subscripts indicate that the mean overall likings scores were different between the Fair Trade and Conventional label in an evaluation context.

Impact of some confounding factors were found, but the impact was depending on the type of product. For chocolate, a significant interaction effect of the label with the frequency of purchasing Fair Trade products was found $(\mathrm{F}(1,175)=5.821, p=0.017)$. Paired-sample $t$-tests for each group indicated that the labelling effect only manifested in the group of participants with a higher buying frequency of Fair Trade products $(t(79)=3.131, p=0.002)$. When a chocolate was labelled as Fair Trade, the overall liking increased from 6.5 (S.D. $=1.6$ ) to 7.0 (S.D. = 1.3). A significant interaction effect of the label with the personal values was only found for juice $(\mathrm{F}(1,175)=5.127, p=0.025)$. An effect of the Fair Trade label on the overall liking score of juice was only found for persons with a higher score on the personal values $(t(96)=4.402, p<0.001)$. The mean overall liking score for the juice foreseen with a Fair Trade label was 6.5 (S.D. $=1.4)$ compared to a mean overall liking score of 6.0 (S.D. = 1.7) when the juice was labelled as conventional for persons with a higher score on personal values. Regarding involvement, only a significant interaction effect with the label was found for the nuts $(\mathrm{F}(1,175)=6.336, p=0.13)$. The mean overall liking score was significantly higher (6.8 compared 6.4) if the nuts were foreseen with a Fair Trade label when people had a higher involvement with Fair Trade products $(\mathrm{t}(82)=3.460), p=0.001)$. No effect of the Fair Trade label was found on the liking scores for the group with a lower involvement with Fair Trade products ( $\mathrm{t}(95)=-0.93, p=0.926)$.

\subsection{WTP}

The 3-way ANOVA indicated a significant interaction effect of Product $X$ Label $(\mathrm{F}(1.907,337.488)=4.872, p=0.009)$. A higher WTP found for the juice when it was foreseen from a Fair Trade label while the Fair Trade label did not affect the WTP for the nuts or chocolate. All mean WTP for each product in each context are in Table 4.

Table 4. Mean and S.D. WTP scores $(€)$ for the labelled products separately for the CLT $(n=90)$ and HUT ( $n=89)$ context.

\begin{tabular}{cccccc}
\hline & \multicolumn{2}{c}{ Fair Trade } & \multicolumn{2}{c}{ Conventional } \\
\cline { 2 - 6 } & Mean & S.D. & Mean & S.D. & $p$ \\
\hline CLT & & & & & \\
Chocolate & 1.24 & 0.78 & 1.13 & 0.73 & 0.182 \\
Juice & 1.16 & 0.80 & 0.93 & 0.64 & $<0.001$ \\
Nuts & 1.14 & 0.71 & 1.23 & 0.85 & 0.234 \\
\hline HUT & & & & & \\
Chocolate & 1.16 & 0.65 & 1.12 & 0.63 & 0.479 \\
Juice & 1.16 & 0.67 & 1.01 & 0.63 & 0.006 \\
Nuts & 1.21 & 0.76 & 1.12 & 0.70 & 0.069 \\
\hline
\end{tabular}


Regarding the confounding factors, only an influence was found for the involvement on the WTP for the nuts samples $(\mathrm{F}(1,175)=4.454, p=0.036)$. While a higher WTP for the Fair Trade nuts $(€ 1.17)$ compared to the conventional nuts $(€ 1.08)$ was found for persons with a higher Fair Trade involvement ( $\mathrm{t}(82), p=0.166)$, the mean WTP for the conventional labelled $(€ 1.25)$ nuts was higher than for Fair Trade labelled nuts $(€ 1.18)$ for persons with a lower Fair Trade involvement $(\mathrm{t}(95)=-1.244, p=0.216)$.

\subsection{Kcal Estimation}

No significant interaction effect was found for the three-way ANOVA. The only main effect found was for the products $(\mathrm{F}(2,354)=9.886, p<0.001)$ indicating that the caloric estimation of a snack portion of chocolate was significantly higher than that of juice or nuts. Mean kcal estimations are listed in Table 5.

Table 5. Mean caloric estimations ( $\mathrm{kCal})$ for the labelled products separately for the CLT $(n=90)$ and HUT $(n=89)$ context.

\begin{tabular}{cccccc}
\hline & \multicolumn{2}{c}{ Fair Trade } & \multicolumn{2}{c}{ Conventional } \\
\cline { 2 - 6 } & Mean & S.D. & Mean & S.D. & $p$ \\
\hline CLT & & & & & \\
Chocolate & 162 & 148 & 166 & 154 & 0.178 \\
Juice & 109 & 90 & 109 & 88 & 0.982 \\
Nuts & 136 & 131 & 135 & 127 & 0.793 \\
\hline HUT & & & & & \\
Chocolate & 164 & 103 & 165 & 106 & 0.626 \\
Juice & 133 & 107 & 135 & 112 & 0.617 \\
Nuts & 132 & 114 & 137 & 122 & 0.400 \\
\hline
\end{tabular}

A three way effect of nutrition label $x$ context $x$ Fair Trade label was found for the chocolate products. However, paired samples t-test did not indicate significant differences.

\subsection{Sensory Profiling}

Only a limited impact was found of the Fair Trade label on consumers' perception of the sensory properties of the products. Both at the CLT and HUT, more participants indicated that 'naturalness' was applicable for the nuts when it was labelled as Fair Trade. While no impact was found of the Fair Trade label on the chocolate during the CLT test $(p>0.05)$, more participants of the HUT experienced 'mouthfeel' for the chocolate when it was labelled as 'conventional'. Lastly, for the juice, more persons executing the task at the lab indicated that 'naturalness' was applicable for the chocolate when it was labeled as 'Fair Trade' compared to when it was labelled as 'conventional'. On the other hand, only the sensory perception of 'sweetness' was influenced by the Fair Trade label when participants evaluated the samples at home. More persons indicated there that the Fair Trade juice was 'sweet' (Tables 6 and 7). 
Table 6. Usage frequencies (in \% respondents) of the sensory attributes for the Fair Trade (FT) and conventional (conv) products in the CLT $(n=90)$ context.

\begin{tabular}{ccccccccc}
\hline Nuts & FT & Conv & Chocolate & FT & Conv & Juice & FT & Conv \\
\hline Bitter & 0 & 6 & Aftertaste & 6 & 6 & Aftertaste & 22 & 24 \\
Bland & 27 & 36 & Bitter & 68 & 67 & Bitter & 18 & 16 \\
Brown color & 14 & 13 & Brown & 32 & 39 & Intense flavor * & 41 & 24 \\
Chicken stock & 2 & 4 & Cocoa aroma & 27 & 32 & Light color & 21 & 20 \\
Crunchy & 61 & 59 & Cocoa flavor & 14 & 13 & Natural taste* & 38 & 24 \\
Dry & 42 & 46 & Creamy & 86 & 86 & Off-flavor & 8 & 10 \\
Earthy & 16 & 16 & Firm & 52 & 44 & Orange aroma & 54 & 51 \\
Natural & 74 & 58 & Granular & 53 & 48 & Orange color & 52 & 50 \\
Oily & 27 & 26 & Melting & 51 & 44 & Orange flavor & 60 & 52 \\
Roasted & 32 & 27 & Milky & 7 & 9 & Pulp & 7 & 10 \\
Salty & 12 & 18 & Mouthfeel & 10 & 13 & Sour & 52 & 44 \\
Sweet & 28 & 22 & Smooth & 29 & 23 & Sweet & 47 & 43 \\
Visible salt & 2 & 3 & Sticky & 26 & 20 & Thick & 6 & 4 \\
& & & Sweet & 57 & 57 & Watery & 36 \\
\hline
\end{tabular}

* indicates a significant difference in usage frequency between the Fair Trade and conventional labels for that specific attribute at $p<0.05$.

Table 7. Usage frequencies (in \% respondents) of the sensory attributes for the Fair Trade (FT) and conventional (conv) products in the HUT $(n=89)$ context.

\begin{tabular}{ccccccccc}
\hline Nuts & FT & Conv & Chocolate & FT & Conv & Juice & FT & Conv \\
\hline Bitter & 6 & 9 & Aftertaste & 16 & 9 & Aftertaste & 36 & 28 \\
Bland & 17 & 27 & Bitter & 64 & 58 & Bitter & 27 & 22 \\
Brown color & 27 & 22 & Brown & 34 & 33 & Intense flavor & 25 & 21 \\
Chicken stock & 0 & 1 & Cocoa aroma & 35 & 30 & Light color & 16 & 19 \\
Crunchy & 49 & 47 & Cocoa flavor & 30 & 30 & Natural taste & 40 & 33 \\
Dry & 52 & 51 & Creamy & 76 & 70 & Off-flavor & 8 & 13 \\
Earthy & 26 & 30 & Firm & 55 & 51 & Orange aroma & 47 & 48 \\
Natural & 64 & 48 & Granular & 40 & 42 & Orange color & 62 & 64 \\
Oily & 35 & 33 & Melting & 37 & 39 & Orange flavor & 62 & 57 \\
Roasted & 25 & 20 & Milky & 15 & 21 & Pulp & 4 & 3 \\
Salty & 26 & 30 & Mouthfeel & 8 & 16 & Sour & 46 & 51 \\
Sweet & 26 & 22 & Smooth & 26 & 22 & Sweet * & 42 & 29 \\
Visible salt & 0 & 1 & Sticky & 35 & 28 & Thick & 10 & 8 \\
& & Sweet & 56 & 51 & Watery & 40 & 52 \\
\hline
\end{tabular}

* indicates a significant difference in usage frequency between the Fair Trade and conventional labels for that specific attribute at $p<0.05$.

\subsection{Emotional Profiling}

In line with the sensory profiling, only limited impact of the Fair Trade label was found on the emotional profiling of the samples with even no impact at all for the juice samples. For the nuts, more participants at the CLT indicated that 'contented' was applicable for the Fair Trade labelled nuts compared to the conventional labelled nuts. In contrary, only a difference in the usage frequency of 'bored' was found for the participants at the HUT with more participants indicating a feeling of bored for the conventionally labeled nuts than the Fair Trade label nuts. For the chocolate, on one hand more people at the CLT checked 'calm' and 'disappointed' for the conventionally labeled chocolate than the Fair Trade labelled chocolate. On the other hand, people of the HUT used more the emotion 'pleasant' for the Fair Trade labelled chocolate compared to the conventionally labeled chocolate (Tables 8 and 9). 
Table 8. Usage frequencies (in \% respondents) of the emotional for the Fair Trade (FT) and conventional (conv) products in the CLT $(n=90)$ context.

\begin{tabular}{|c|c|c|c|c|c|c|c|c|}
\hline Nuts & FT & Conv & Chocolate & FT & Conv & Juice & FT & Conv \\
\hline Bored & 13 & 20 & Calm * & 13 & 23 & Calm & 14 & 20 \\
\hline Calm & 20 & 22 & Desire & 13 & 11 & Desire & 8 & 6 \\
\hline Contented * & 37 & 21 & Disappointed * & 4 & 12 & Disappointed & 11 & 20 \\
\hline Disappointed & 7 & 10 & Discontented & 4 & 2 & Discontented & 9 & 12 \\
\hline Discontented & 0 & 2 & Disgust & 1 & 1 & Disgust & 2 & 3 \\
\hline Disgust & 0 & 0 & Dissatisfied & 8 & 10 & Dissatisfied & 12 & 16 \\
\hline Dissatisfied & 7 & 7 & Energetic & 11 & 10 & Energetic & 17 & 10 \\
\hline Friendly & 13 & 12 & Enthusiastic & 17 & 12 & Enthusiastic & 12 & 9 \\
\hline Frustrated & 1 & 3 & Glad & 32 & 26 & Glad & 20 & 14 \\
\hline Good & 41 & 40 & Good & 46 & 41 & Good & 40 & 38 \\
\hline Happy & 16 & 19 & Guilty & 2 & 0 & Guilty & 0 & 0 \\
\hline Interested & 16 & 7 & Happy & 40 & 40 & Happy & 22 & 22 \\
\hline Irritated & 0 & 0 & Irritated & 1 & 0 & Irritated & 7 & 8 \\
\hline Joyful & 9 & 6 & Nostalgic & 12 & 12 & Pleasant & 17 & 16 \\
\hline Pleasantly surprised & 14 & 9 & Pleasant & 31 & 30 & Sad & 0 & 1 \\
\hline Satisfied & 29 & 26 & Sad & 0 & 1 & Satisfied & 28 & 20 \\
\hline Steady & 8 & 7 & Satisfied * & 38 & 26 & Unpleasantly surprised & 1 & 1 \\
\hline Unpleasantly surprised & 2 & 8 & Unpleasantly surprised & 4 & 2 & Warm & 3 & 0 \\
\hline & & & Worried & 1 & 0 & Worried & 4 & 7 \\
\hline
\end{tabular}

* indicates a significant difference in usage frequency between the Fair Trade and conventional labels for that specific emotion at $p<0.05$.

Table 9. Usage frequencies (in \% respondents) of the emotional terms for the Fair Trade (FT) and conventional (conv) products in the HUT $(n=89)$ context.

\begin{tabular}{|c|c|c|c|c|c|c|c|c|}
\hline Nuts & FT & Conv & Chocolate & FT & Conv & Juice & FT & Conv \\
\hline Bored * & 8 & 19 & Calm & 15 & 16 & Calm & 15 & 21 \\
\hline Calm & 19 & 13 & Desire & 27 & 27 & Desire & 18 & 19 \\
\hline Contented & 20 & 16 & Disappointed & 2 & 6 & Disappointed & 9 & 13 \\
\hline Disappointed & 9 & 11 & Discontented & 3 & 4 & Discontented & 10 & 8 \\
\hline Discontented & 7 & 8 & Disgust & 1 & 3 & Disgust & 2 & 2 \\
\hline Disgust & 3 & 3 & Dissatisfied & 9 & 13 & Dissatisfied & 12 & 12 \\
\hline Dissatisfied & 11 & 10 & Energetic & 15 & 11 & Energetic & 11 & 6 \\
\hline Friendly & 10 & 12 & Enthusiastic & 15 & 10 & Enthusiastic & 8 & 4 \\
\hline Frustrated & 3 & 0 & Glad & 27 & 28 & Glad & 25 & 24 \\
\hline Good & 42 & 40 & Good & 51 & 47 & Good & 49 & 51 \\
\hline Happy & 25 & 24 & Guilty & 10 & 9 & Guilty & 4 & 6 \\
\hline Interested & 20 & 21 & Happy & 43 & 33 & Happy & 30 & 27 \\
\hline Irritated & 1 & 0 & Irritated & 1 & 2 & Irritated & 3 & 6 \\
\hline Joyful & 15 & 9 & Nostalgic & 7 & 6 & Pleasant & 24 & 21 \\
\hline Pleasantly surprised & 20 & 18 & Pleasant * & 35 & 21 & Sad & 1 & 0 \\
\hline Satisfied & 28 & 25 & Sad & 1 & 1 & Satisfied & 19 & 20 \\
\hline Steady & 9 & 9 & Satisfied & 33 & 25 & Unpleasantly surprised & 6 & 1 \\
\hline \multirow[t]{2}{*}{$\begin{array}{l}\text { Unpleasantly } \\
\text { surprised }\end{array}$} & 9 & 11 & $\begin{array}{l}\text { Unpleasantly } \\
\text { surprised }\end{array}$ & 4 & 3 & Warm & 3 & 4 \\
\hline & & & Worried & 6 & 6 & Worried & 10 & 7 \\
\hline
\end{tabular}

${ }^{*}$ indicates a significant difference in usage frequency between the Fair Trade and conventional labels for that specific emotion at $p<0.05$.

\section{Discussion}

The aim of the research was to determine if consumer's perceptions of food products is altered by Fair Trade labels and if this potential effect is context dependent. This study found that the Fair Trade label had a general positive effect on consumer's liking of the product and to the WTP of two products, regardless of the evaluation context. The Fair Trade label did not influence the kcal estimations of the products. Also, the effect of the Fair 
Trade label on consumers' perception of the sensory attributes and associated emotions of the product samples was very limited and differed between the evaluation contexts.

Labelling food products with a Fair Trade label increased overall acceptance compared to a conventional label; this is in congruence with previous research performed at CLT's indicating that Fair Trade labels have an overall positive impact on overall liking scores [9]. However, the present study only provided written information about the production method while other studies included the Fair Trade logo [22,24] or package [23]. It should be noted that the overall effect of the Fair Trade label on the liking scores was rather small. Furthermore, this study used a within-subjects design while the previous mentioned studied opted to work with a between-subjects design. Given that no interaction effect of the label with the context was found, the effect can be seen as independent of the evaluation context and therefore expanding current knowledge. Furthermore, it should be stated that a higher positive effect of the Fair Trade on the liking scores was found for some confounding factors (purchase frequency, Fair Trade involvement and personal values). However, the effect only manifested each time in one of the three product samples.

The influence of the Fair Trade label on the evaluation of the sensory attributes was limited, with even a maximum of 2 significant different attributes for a product. For nuts, both at the HUT and CLT, samples foreseen with the description of 'Fair Trade' were seen by more participants as 'natural'. More consumers found that the juice had a 'natural taste' at the CLT, while no effect of the label regarding the 'natural taste' was established at the HUT. Previous research indicated that some consumers displayed confusion between organic (which is often linked with naturalness) and Fair Trade products which might explain the association of Fair Trade products with naturalness [50]. Also, Fair Trade products are associated with naturalness in The Eating Motivation Survey (TEMS) [51]. Furthermore, more participants indicated that the orange juice was 'sweet' when labelled as Fair Trade at the HUT. The study of Poelman, Mojet, Lyon and Sefa-Dedeh [21] found that consumers might perceive pineapple as sweeter when it is labelled as Fair Trade but their study was performed at a CLT. So it might be that the sweetness perception of the fruit or products based upon fruit (like fruit juice) is influenced by a Fair Trade label but that this effect is depending on the evaluation context and might different depending on the type of fruit and/or processing. Although more research is warranted, it looks that the Fair Trade label had only a limited impact on the sensory profiling of the product samples but that the influence could differ depending on the context. However, when an impact was established, it was a positive impact.

A rather limited impact of the Fair Trade label was found on consumer's emotions associated with the food products, with even no effect for the juice samples. While more participants at the CLT indicated that 'contented' was applicable for the nuts foreseen with a Fair Trade label compared to the conventionally labeled nuts, more participants of the HUT associated 'bored' with the conventionally labeled nuts than with the Fair Trade labeled nuts. For the chocolate sample, more participants linked the neutral term 'calm' and the negative term 'disappointed' with the conventionally labeled sample while more consumers used the positive term 'satisfied' for the Fair Trade labeled chocolate sample at the CLT. When tasting the chocolate at the HUT, the only difference was for 'pleasant' with more participants association this positive feeling with the Fair Trade labelled product compared to the conventionally labeled product. In short, when an effect of the label was established on the products, it was so that the Fair Trade label lead to positive associations with more consumers or that the conventionally labeled was evoking more negative emotions. The limited effect of the label on the emotional associations could be due to the fact that participants were actually evaluating the same samples but labelled differently. Previous research stated that emotional associations are mainly sensory driven [52-55] so this might explain the limited effect of the label on the emotions, especially as the sensory profiling indicated that participants perceived little sensory differences between the samples of a pair. 
WTP was higher when the juice was foreseen of a Fair Trade label while no label effect was found for the other two products. Previous research carried out at CLT indicated that consumers were willing to pay more for Fair Trade labelled coffee $[5,15,16]$, yellow chili peppers [17] and chocolate [18-20] although the price premium was limited to certain consumer segments. The findings in the present research extend these findings for juice (both at the CLT and HUT), but were not able to confirm them for chocolate regardless of the evaluation context. However, a recent study found that third-party labels (such as Fair Trade) were not effective in influencing young consumers' WTP for chocolate when they were not accompanied of self-declared claim (e.g., "the product wrap is made from $100 \%$ recycled paper") [56]. So a potential impact for chocolate might be depending on the consumer segment and more research is warranted on the effect of additional claims on the package. Another possibility why the WTP differed between the products is that consumers might only be willing to pay more for a Fair Trade product when they believe that the label signals higher quality (e.g., the product is healthier) [57]. From this point of view, the WTP is more based on egoistic reasons than altruistic for Fair Trade labels as consumers are not willing to pay a price premium in order to guarantee a sufficient pay for small-scale farmers and producers in the global South. A study by Ruggeri, et al. [58] found that Italian consumers were willing to pay more for Fair Trade certified sugar during auctions, especially when information about Fair Trade was provided. It might be interesting that future research with auctions also consider the sensory dimension to examine if that might impact the WTP.

No effect of the Fair Trade label on the kcal estimations was found in this study. This contradicts with the previous findings by Schuldt, Muller and Schwarz [25] who found that consumers provided lower kcal estimations when chocolate was labelled as Fair Trade during a CLT. However, it should be noted that the effect by Schuldt, Muller and Schwarz [25] was rather limited $(p=0.03)$, another type of question was used ('Compared to other brands of chocolate, how many calories do you think that one serving of Petersen's [fairtrade] chocolate contains') and they applied another research design (between-subjects design).

There is a growing call in the field of sensory and consumer research to include more measurements in realistic eating/purchase contexts, like at home, in a restaurant or in the supermarket to increase the ecological validity [31,36]. To the best of the authors knowledge, all prior studies examining the impact of Fair Trade labels on consumer's evaluation of food products were carried out at a CLT. In this study, results were rather consistent regardless of the testing context (HUT and CLT) indicating that the CLT might be a more cost-effective evaluation context which delivers similar results as the HUT. Only some small differences were found for specific sensory attributes and emotional terms. Several potential factors could explain the influence of the evaluation context on the sensory and emotional profiling of the samples. A first reason is that participants are more aware that they are participating in a scientific experiment when it takes place in a standardized lab in a CLT setting. As a result, this CLT context could generate a more analytical mindset compared to the HUT [59]. Second, participants at the HUT could be influenced by social interaction while participants of the CLT were seated in individual booths which limits potential interaction from other persons [47]. Third, the time of the consumption might have been more appropriate when participants were able to conduct the test when they wanted during the HUT while the participants of the CLT needed to evaluate the samples at a fixed time during working hours [59].

From a theoretical point of view, two potential drivers could be responsible for the positive effect of Fair Trade labels. First, a so-called halo effect could have occurred [21]. Due to participants' associations with the label, actual changes in the perceptual input result in different neural processing of the taste experience [60]. The psychological effects are then due to the beliefs and attitudes of the participants towards the label. As a results, the effects can be either negative or positive and may vary in magnitude. Second, other research indicated that positive affect can explain the positive effect of Fair Trade labels on 
consumer's evaluation of food products [23]. Fair Trade labels are seen as ethical labels yielding positive affect which is transferred to the product [61]. Results of Lotz, Christandl and Fetchenhauer [23] suggest that the positive effect of ethical labels goes beyond a haloeffect based on automatic cognitive heuristics, but also results from emotional processes. The results of this study also found that Fair Trade could, to some extent, induce more positive emotional associations. However, a potential influence by affect should be studied more in depth using neuro-imaging methods [62].

Further, some limitations of the present study should be mentioned. As in most sensory studies, this study worked with a convenient sample which consisted predominantly of younger persons. The self-reported buying frequency of Fair Trade products was also high [63]. Also, this study applied a between-subject design which resulted in some differences between the CLT and HUT groups (e.g., hungry and restraint status). Given the limited significant differences in the results between the CLT and HUT groups, it appears that these differences did not have a large influence on the results. The researchers decided to only included three pairs of samples, considering practical constraints and sensory satiety when participants need to evaluate the samples during a single session. Research on other food products is warranted, but this study goes beyond previous research which typically focused on the effect of Fair Trade label on a single food product. Given that samples were served in pairs, one need to consider that participants could be biased as the samples might look similar. However, none of the respondents indicated in the open question that they thought that all the samples were identical. Lastly, the order of the questions might have played a role (first overall liking, then sensory profiling followed by the emotional profiling). Previous research indicated a lack of CATA questions on the overall liking scores [64]. It could be that the overall liking and sensory profiling induced a more analytical mindset which impacted the emotional profiling task. Lastly, one should note that WTP was measured by directly asking participants how much they are willing to pay for each sample. Although this is a common measure to assess WTP during sensory experiments, other techniques are available to assess WTP during like contingent valuation [65], auctions [65,66] and conjoint analysis [5,65]. We recommend that future research might compare different methods to assess WTP when the focus of the study is determine the WTP of Fair Trade labelled products.

\section{Conclusions}

Previous research indicated that extrinsic cues could influence consumer' perception of food products [62,67]. This study adds that such effect also occurs when using Fair Trade labels and that this effect is not impacted by the evaluation context (HUT and CLT). An increased WTP was depending on the product type while the Fair Trade label did not influence the kcal estimations of the participants. The Fair Trade label also leads to the perception that the products are more natural while little impact was found on the other sensory attributes and on emotional associations. The evaluation context did affect the sensory and emotional profiling of certain products.

Author Contributions: Conceptualization, J.J.S. and H.S.; methodology, J.J.S., X.G. and H.S.; formal analysis, J.J.S. and H.S.; investigation, J.J.S., X.G. and H.S.; resources, X.G.; data curation, J.J.S. and H.S.; writing—original draft preparation, J.J.S., X.G. and H.S.; writing—review and editing, X.G.; visualization, J.J.S. and H.S.; supervision, X.G. and H.S.; project administration, J.J.S. and H.S. All authors have read and agreed to the published version of the manuscript.

Funding: This research received no external funding.

Institutional Review Board Statement: The study was conducted according to the guidelines of the Declaration of Helsinki, and approved by the Ethical committee of the Faculty of Economics and Business administration at Ghent University on 18 February 2019.

Informed Consent Statement: Informed consent was obtained from all subjects involved in the study. 
Data Availability Statement: Due to the nature of this research, participants of this study did not agree for their data to be shared publicly, so supporting data is not available.

Conflicts of Interest: The authors declare no conflict of interest.

\section{References}

1. Konuk, F.A. Consumers' willingness to buy and willingness to pay for fair trade food: The influence of consciousness for fair consumption, environmental concern, trust and innovativeness. Food Res. Int. 2019, 120, 141-147. [CrossRef]

2. Zander, K.; Hamm, U. Consumer preferences for additional ethical attributes of organic food. Food Qual. Prefer. 2010, 21, 495-503. [CrossRef]

3. Manning, S.; Boons, F.; Von Hagen, O.; Reinecke, J. National contexts matter: The co-evolution of sustainability standards in global value chains. Ecol. Econ. 2012, 83, 197-209. [CrossRef]

4. Bosbach, M.; Maietta, O.W. The Implicit Price for Fair Trade Coffee: Does Social Capital Matter? Ecol. Econ. 2019, 158, 34-41.

5. Van Loo, E.J.; Caputo, V.; Nayga, R.M., Jr.; Seo, H.-S.; Zhang, B.; Verbeke, W. Sustainability labels on coffee: Consumer preferences, willingness-to-pay and visual attention to attributes. Ecol. Econ. 2015, 118, 215-225. [CrossRef]

6. Dammert, A.C.; Mohan, S. A survey of the economics of fair trade. J. Econ. Surv. 2015, 29, 855-868.

7. Le Mare, A. The impact of fair trade on social and economic development: A review of the literature. Geogr. Compass 2008, 2, 1922-1942. [CrossRef]

8. Fairtrade International. Sustainable Development Goals (SDGS). Available online: https://www.fairtrade.net/issue/sdgs (accessed on 16 January 2021).

9. O'Connor, E.L.; Sims, L.; White, K.M. Ethical food choices: Examining people's Fair Trade purchasing decisions. Food Qual. Prefer. 2017, 60, 105-112. [CrossRef]

10. Fernqvist, F.; Ekelund, L. Credence and the effect on consumer liking of food-A review. Food Qual. Prefer. 2014, 32 Pt C, $340-353$

11. Van Loo, E.J.; Grebitus, C.; Verbeke, W. Effects of nutrition and sustainability claims on attention and choice: An eye-tracking study in the context of a choice experiment using granola bar concepts. Food Qual. Prefer. 2020, 104100. [CrossRef]

12. Andorfer, V.A.; Liebe, U. Research on Fair Trade Consumption-A Review. J. Bus. Ethics 2012, 106, 415-435. [CrossRef]

13. Zerbini, C.; Vergura, D.T.; Latusi, S. A new model to predict consumers' willingness to buy fair-trade products. Food Res. Int. 2019, 122, 167-173. [CrossRef]

14. Ajzen, I. The Theory of Planned Behaviour: Reactions and Reflections; Taylor \& Francis: Karnataka, India, 2011.

15. De Pelsmacker, P.; Driesen, L.; Rayp, G. Do consumers care about ethics? Willingness to pay for fair-trade coffee. J. Consum. Aff. 2005, 39, 363-385. [CrossRef]

16. Loureiro, M.L.; Lotade, J. Do fair trade and eco-labels in coffee wake up the consumer conscience? Ecol. Econ. 2005, 53, 129-138. [CrossRef]

17. Garcia, J.-Y. Willingness to pay for organic and Fairtrade certified yellow chili peppers: Evidence from middle and high income districts in Lima, Peru. Br. Food J. 2015, 117, 929-942. [CrossRef]

18. Rousseau, S. The role of organic and fair trade labels when choosing chocolate. Food Qual. Prefer. 2015, 44, 92-100.

19. Didier, T.; Lucie, S. Measuring consumer's willingness to pay for organic and Fair Trade products. Int. J. Consum. Stud. 2008, 32, 479-490. [CrossRef]

20. Vecchio, R.; Annunziata, A. Willingness-to-pay for sustainability-labelled chocolate: An experimental auction approach. J. Clean. Prod. 2015, 86, 335-342.

21. Poelman, A.; Mojet, J.; Lyon, D.; Sefa-Dedeh, S. The influence of information about organic production and fair trade on preferences for and perception of pineapple. Food Qual. Prefer. 2008, 19, 114-121.

22. Grankvist, G.; Lekedal, H.; Marmendal, M. Values and eco- and fair-trade labelled products. Br. Food J. 2007, 109, 169-181. [CrossRef]

23. Lotz, S.; Christandl, F.; Fetchenhauer, D. What is fair is good: Evidence of consumers' taste for fairness. Food Qual. Prefer. 2013, 30, 139-144. [CrossRef]

24. Tang, S.; Arciniegas, C.; Yu, F.; Han, J.; Chen, S.; Shi, J. Taste moral, taste good: The effects of Fairtrade logo and second language on product taste evaluation. Food Qual. Prefer. 2016, 50, 152-156. [CrossRef]

25. Schuldt, J.P.; Muller, D.; Schwarz, N. The "fair trade" effect: Health halos from social ethics claims. Soc. Psychol. Personal. Sci. 2012, 3, 581-589. [CrossRef]

26. Lagast, S.; Gellynck, X.; Schouteten, J.J.; De Herdt, V.; De Steur, H. Consumers' emotions elicited by food: A systematic review of explicit and implicit methods. Trends Food Sci. Technol. 2017, 69 Pt A, 172-189. [CrossRef]

27. Lawless, H.T.; Heymann, H. Sensory Evaluation of Food: Principles and Practices, 2nd ed.; Springer: New York, NY, USA, 2010.

28. Bangcuyo, R.G.; Smith, K.J.; Zumach, J.L.; Pierce, A.M.; Guttman, G.A.; Simons, C.T. The use of immersive technologies to improve consumer testing: The role of ecological validity, context and engagement in evaluating coffee. Food Qual. Prefer. 2015, 41, 84-95. [CrossRef]

29. De Wijk, R.A.; Kaneko, D.; Dijksterhuis, G.B.; van Zoggel, M.; Schiona, I.; Visalli, M.; Zandstra, E.H. Food perception and emotion measured over time in-lab and in-home. Food Qual. Prefer. 2019, 75, 170-178. [CrossRef]

30. Jaeger, S.R.; Hort, J.; Porcherot, C.; Ares, G.; Pecore, S.; MacFie, H.J.H. Future directions in sensory and consumer science: Four perspectives and audience voting. Food Qual. Prefer. 2016, 56 Pt B, 301-309. 
31. Jaeger, S.R.; Porcherot, C. Consumption context in consumer research: Methodological perspectives. Curr. Opin. Food Sci. 2017, 15, 30-37. [CrossRef]

32. Schouteten, J.J.; De Steur, H.; Sas, B.; De Bourdeaudhuij, I.; Gellynck, X. The effect of the research setting on the emotional and sensory profiling under blind, expected, and informed conditions: A study on premium and private label yogurt products. J. Dairy Sci. 2017, 100, 169-186. [CrossRef]

33. Danner, L.; Ristic, R.; Johnson, T.E.; Meiselman, H.L.; Hoek, A.C.; Jeffery, D.W.; Bastian, S.E.P. Context and wine quality effects on consumers' mood, emotions, liking and willingness to pay for Australian Shiraz wines. Food Res. Int. 2016, 89, $254-265$.

34. Nijman, M.; James, S.; Dehrmann, F.; Smart, K.; Ford, R.; Hort, J. The effect of consumption context on consumer hedonics, emotional response and beer choice. Food Qual. Prefer. 2019, 74, 59-71. [CrossRef]

35. Boutrolle, I.; Delarue, J.; Arranz, D.; Rogeaux, M.; Köster, E.P. Central location test vs. home use test: Contrasting results depending on product type. Food Qual. Prefer. 2007, 18, 490-499. [CrossRef]

36. Meiselman, H.L. The future in sensory/consumer research: Evolving to a better science. Food Qual. Prefer. 2013, 27, 208-214. [CrossRef]

37. MacFie, H.J.; Bratchell, N.; Greenhoff, K.; Vallis, L.V. Designs to balance the effect of order of presentation and first-order carry-over effects in hall tests. J. Sens. Stud. 1989, 4, 129-148. [CrossRef]

38. Masic, U.; Christiansen, P.; Boyland, E.J. The influence of calorie and physical activity labelling on snack and beverage choices. Appetite 2017, 112, 52-58. [CrossRef]

39. Schouteten, J.J.; De Steur, H.; De Pelsmaeker, S.; Lagast, S.; De Bourdeaudhuij, I.; Gellynck, X. An integrated method for the emotional conceptualization and sensory characterization of food products: The EmoSensory ${ }^{\circledR}$ Wheel. Food Res. Int. 2015, 78, 96-107. [CrossRef]

40. Ares, G.; Bruzzone, F.; Giménez, A.N.A. Is a consumper panel able to reliably evaluate the texture of dairy desserts using unstructured intensity scales? Evaluation of global and individual performance. J. Sens. Stud. 2011, 26, 363-370. [CrossRef]

41. Van Kleef, E.; Shimizu, M.; Wansink, B. Serving bowl selection biases the amount of food served. J. Nutr. Educ. Behav. 2012, 44, 66-70. [CrossRef]

42. Lee, W.-C.J.; Shimizu, M.; Kniffin, K.M.; Wansink, B. You taste what you see: Do organic labels bias taste perceptions? Food Qual. Prefer. 2013, 29, 33-39. [CrossRef]

43. Schouteten, J.J.; Gellynck, X.; Slabbinck, H. Influence of organic labels on consumer's flavor perception and emotional profiling: Comparison between a central location test and home-use-test. Food Res. Int. 2019, 116, 1000-1009. [CrossRef]

44. Van Strien, T.; Frijters, J.E.R.; Bergers, G.P.A.; Defares, P.B. The Dutch Eating Behavior Questionnaire (DEBQ) for assessment of restrained, emotional, and external eating behavior. Int. J. Eat. Disord. 1986, 5, 295-315. [CrossRef]

45. Van Loo, E.J.; Diem, M.N.H.; Pieniak, Z.; Verbeke, W. Consumer attitudes, knowledge, and consumption of organic yogurt. J. Dairy Sci. 2013, 96, 2118-2129. [CrossRef] [PubMed]

46. Ladhari, R.; Tchetgna, N.M. The influence of personal values on Fair Trade consumption. J. Clean. Prod. 2015, 87, 469-477. [CrossRef]

47. Hersleth, M.; Ueland, Ø.; Allain, H.; Næs, T. Consumer acceptance of cheese, influence of different testing conditions. Food Qual. Prefer. 2005, 16, 103-110. [CrossRef]

48. Pramudya, R.C.; Seo, H.-S. Using Check-All-That-Apply (CATA) method for determining product temperature-dependent sensory-attribute variations: A case study of cooked rice. Food Res. Int. 2018, 105, 724-732. [CrossRef]

49. Schouteten, J.J.; Gellynck, X.; De Bourdeaudhuij, I.; Sas, B.; Bredie, W.L.P.; Perez-Cueto, F.J.A.; De Steur, H. Comparison of response formats and concurrent hedonic measures for optimal use of the EmoSensory ${ }^{\circledR}$ Wheel. Food Res. Int. 2017, $93,33-42$. [CrossRef]

50. McEachern, M.; Seaman, C.; Padel, S.; Foster, C. Exploring the gap between attitudes and behaviour. Br. Food J. 2005, 107, 606-625.

51. Renner, B.; Sproesser, G.; Strohbach, S.; Schupp, H.T. Why we eat what we eat. The Eating Motivation Survey (TEMS). Appetite 2012, 59, 117-128. [CrossRef]

52. Gutjar, S.; de Graaf, C.; Kooijman, V.; de Wijk, R.A.; Nys, A.; ter Horst, G.J.; Jager, G. The role of emotions in food choice and liking. Food Res. Int. 2015, 76, 216-223. [CrossRef]

53. Ng, M.; Chaya, C.; Hort, J. The influence of sensory and packaging cues on both liking and emotional, abstract and functional conceptualisations. Food Qual. Prefer. 2013, 29, 146-156. [CrossRef]

54. Schouteten, J.J.; De Steur, H.; De Pelsmaeker, S.; Lagast, S.; De Bourdeaudhuij, I.; Gellynck, X. Impact of Health Labels on Flavor Perception and Emotional Profiling: A Consumer Study on Cheese. Nutrients 2015, 7, 5533. [CrossRef] [PubMed]

55. Spinelli, S.; Masi, C.; Zoboli, G.P.; Prescott, J.; Monteleone, E. Emotional responses to branded and unbranded foods. Food Qual. Prefer. 2015, 42, 1-11. [CrossRef]

56. Rossi, C.; Rivetti, F. Assessing Young Consumers' Responses to Sustainable Labels: Insights from a Factorial Experiment in Italy. Sustainability 2020, 12, 10115. [CrossRef]

57. Grunert, K.G. Food quality and safety: Consumer perception and demand. Eur. Rev. Agric. Econ. 2005, 32, 369-391. [CrossRef]

58. Ruggeri, G.; Corsi, S.; Nayga, R.M. Eliciting willingness to pay for fairtrade products with information. Food Qual. Prefer. 2021, 87, 104066. [CrossRef]

59. Boutrolle, I.; Arranz, D.; Rogeaux, M.; Delarue, J. Comparing central location test and home use test results: Application of a new criterion. Food Qual. Prefer. 2005, 16, 704-713. [CrossRef] 
60. Sörqvist, P.; Haga, A.; Langeborg, L.; Holmgren, M.; Wallinder, M.; Nöstl, A.; Seager, P.B.; Marsh, J.E. The green halo: Mechanisms and limits of the eco-label effect. Food Qual. Prefer. 2015, 43, 1-9. [CrossRef]

61. Schwarz, N.; Clore, G.L. Feelings and phenomenal experiences. Soc. Psychol. Handb. Basic Princ. 1996, 2, $385-407$.

62. Bratanova, B.; Vauclair, C.-M.; Kervyn, N.; Schumann, S.; Wood, R.; Klein, O. Savouring morality. Moral satisfaction renders food of ethical origin subjectively tastier. Appetite 2015, 91, 137-149. [CrossRef]

63. Fairtrade Belgium. Jaarverslag 2018, 2019, 20.

64. Jaeger, S.R.; Ares, G. Lack of evidence that concurrent sensory product characterisation using CATA questions bias hedonic scores. Food Qual. Prefer. 2014, 35, 1-5. [CrossRef]

65. Grunert, K.G.; Juhl, H.J.; Esbjerg, L.; Jensen, B.B.; Bech-Larsen, T.; Brunsø, K.; Madsen, C.Ø. Comparing methods for measuring consumer willingness to pay for a basic and an improved ready made soup product. Food Qual. Prefer. 2009, 20, 607-619. [CrossRef]

66. Combris, P.; Bazoche, P.; Giraud-Héraud, E.; Issanchou, S. Food choices: What do we learn from combining sensory and economic experiments? Food Qual. Prefer. 2009, 20, 550-557. [CrossRef]

67. Piqueras-Fiszman, B.; Spence, C. Sensory expectations based on product-extrinsic food cues: An interdisciplinary review of the empirical evidence and theoretical accounts. Food Qual. Prefer. 2015, 40, 165-179. [CrossRef] 